\title{
Effect of crop management and cultivar on colonization of Capsicum annuum L. by Endophytic Fungi
}

\author{
Krisztián HALÁSZ, Csaba BORBÉLY, Veronika PÓS, \\ László GÁSPÁR, Neda HADDADDERAFSHI, \\ Zsófia WINTER, Noémi LUKÁCS \\ Corvinus University of Budapest, Faculty of Horticulture, \\ Department of Plant Physiology and Plant Biochemistry, Budapest, \\ e-mail: noemi.lukacs@uni-corvinus.hu (corresponding author)
}

Manuscript received November 24, 2015; revised Nov. 30, 2016; Accepted Dec. 3, 2015

\begin{abstract}
Due to their importance as biological control agents, we analysed the colonization of two pepper (Capsicum annuиm L.) cultivars by culturable endophytic fungi in natural sandy soil in the open field and under soil-free conditions in the greenhouse, respectively. In natural soil, we observed a significant difference in colonization rates between the cultivars 'Hó' and 'Kápia'. Colonization rates were always lower in the greenhouse than in the open field. Colonization was enhanced towards the end of the growing period and organ-specific differences were also observed. On the basis of colony morphology, 15 separate groups were identified for future sequence-based identification.
\end{abstract}

Keywords: soil-free culture, culturable endophytes, colonization rate, organ specificity

\section{Introduction}

In the last few decades, it has become generally known that practically all plants studied so far host endophytic microorganisms, among them endophytic fungi. Endophytic fungi are defined as fungi that colonize plant tissue for a considerable period of their life cycle without causing any symptoms in the host plant. Their interaction with the host is intriguingly complex, ranging from mutualism to commensalism and parasitism [1,2]. Many publications demonstrate that endophytes can influence the biosynthetic pathways of the host and even contribute to the synthesis of secondary metabolites or plant hormones, possibly indicating mutual adaptation during the evolutionary process [2-6]. Nevertheless, many aspects of the 
plant-endophyte interaction remain unresolved: it is not clear what genetic and biochemical features are responsible for colonization and for the type of interaction. It is not even known whether plants would be fit enough to survive in their natural environment without their microbial endophytes $[3,4]$.

Answering these questions is of great practical importance since mutualistic endophytic fungi can stimulate plant growth, enhance tolerance to abiotic stressors, such as drought, and may confer resistance against pathogens or herbivores [5-9]. Moreover, it is now widely recognized that the use of selected endophytic fungi as biological control agents could open new approaches in crop management. Biological control offers an attractive, environmentally friendly approach to reduce the use of chemicals, and it can be incorporated into an effective integrated pest management system [9-11]. Biological control is especially desirable for those horticultural plants that are continuously harvested and are consumed unprocessed. In these cultures, the use of fungicides and pesticides interferes with regular harvest, while the toxic products of pathogenic organisms present a health risk to consumers.

Bell pepper (Capsicum annuum L.) belongs in this latter category of vegetables. It is an economically important cash crop grown in greenhouses or open fields worldwide. It is consumed either raw or in processed form, chili powder and paprika being some of the most frequently used spices.

Unfortunately, the growth conditions of bell pepper (hot weather, especially when combined with the climatic conditions of tropical and subtropical regions) strongly favour mould contamination and mycotoxin production, the most important and most dangerous of which are aflatoxins produced by multiple Aspergillus species [12-14]. In addition, production and yield of pepper are strongly influenced by fungal infections that induce wilting, stunted growth, chlorosis, and blotch. Hussain et al. isolated pathogenic fungi from the roots of pepper plants growing on infected sites, and found that Aspergillus flavus, A. niger, Penicillium commune, and Trichoderma harzianum were able to confer protection against them [15]. Similarly, Bae et al. [16] were also able to protect pepper against Phytophtora capsici by using various Trichoderma species. At the end of their experiments, 26-60\% of the Trichoderma-treated plants were free of symptoms, while in the control only $0-10 \%$ stayed healthy. In yet another study, the presence of endophytic fungi has been shown to inhibit the growth, virility, and reproduction of the aphid Aphis gossypii [17]. Some fungal strains even seem appropriate for biological protection, as demonstrated by Martinuz et al., who induced systemic resistance to Aphis gossypii using Fusarium oxysporum Fo162 and Rhizobium etli G12 strains [18]. Others have described protection of chili pepper against Meloidogyne incognita by the combined use of Pasteuria penetrans and Paecilomyces lilacinus [19]. Amongst the natural endophytic fungi of pepper plants, 
Penicillium resedanum, Cladosporium cladosporioides, and Paraconiothyrium sp. have been shown to improve plant growth and confer protection against pathogenic attack and environmental stresses [20, 21].

Because of their potential importance, there have been some studies to identify endophytic fungi in $C$. annum. Amongst these, the most systematic analysis was carried out by Paul et al. in Korea [20]. They collected samples from C. annuum leaves, stem, and root in 3 different phenophases during the year. Out of 900 organ samples, they obtained about 480 fungal isolates belonging to 21 genera. By sequencing the ITS regions, the authors established that the Colletotrichum genus could be found most frequently (18.92\%), followed by Fusarium (18.71\%), Alternaria (7.48\%), and Penicillium (6.24\%). The occurrence and frequency of individual fungus species varied by the phenophases, but Alternaria, Fusarium, and Cladosporium species were present in all developmental stages of pepper [20].

However, most datasets on Capsicum endophytes come from Asia, and it is unknown how representative these results are for peppers grown elsewhere since fungal community structure changes dynamically and is strongly influenced by environment and cultivar $[1,2,22]$. Therefore, due to its importance as a horticultural plant in Hungary, we decided to analyse colonization rates in different organs of pepper and to find out how many fungal morphotypes exist in the plants. Changes were followed from April to October 2013 in the cultivars 'Hó F1' and 'Kárpia F1' cultivated soil-free in greenhouse or in open field. Here we present the results of this analysis.

\section{Materials and methods}

\section{Plant material}

We investigated two pepper (C. annum) cultivars, 'Hó F1' and 'Kápia F1', starting at seedling stage.

Plants were grown in the Research and Experimental Farm of Corvinus University of Budapest (19 03' 01" LE and 47 28' 19" LN) in Soroksár, Central Hungary.

Seeds were sown in February 2013, and all seedlings were grown under greenhouse conditions till the $5^{\text {th }}$ of May. Then, they were transplanted either to an unheated greenhouse to be grown under soil-free conditions in rockwool in double rows (60 and $90 \mathrm{~cm}$ distance) or to an open field in sandy soil in double rows spaced at 40 and $100 \mathrm{~cm}$. The distance between plants was $33 \mathrm{~cm}$ in each row.

Plants were drip-irrigated. Fungicide treatment was not applied at all in the greenhouse and only once (in July) in the open field. 


\section{Sample collection}

Samples were collected at the seedling stage in April and May and from fruiting plants in August and October 2013. We collected young leaves (the topmost fully differentiated leaf), old leaves (the $6-8^{\text {th }}$ leaf counted from top to bottom), young fruits having yellow or green pericarps, biologically ripe, fully coloured fruits, and peduncles of ripe fruits. In addition, young roots and stem samples were also analysed, the latter being taken $15 \mathrm{~cm}$ below the top. Samples were placed in plastic bags and pre-cultivation of potential endophytic fungi was started within 6 hours of collection.

\section{Cultivation of endophytic fungi}

Surface sterilization of the samples was achieved by soaking them in $70 \%$ ethanol for $1 \mathrm{~min}$, then in $20 \%$ hypochlorite solution for $10 \mathrm{~min}$, followed by a final rinse in $70 \%$ ethanol for 1 minute. Finally, samples were washed in sterile distilled water.

Surface-sterilized samples of about $5 \times 5 \mathrm{~mm}$ were prepared under sterile conditions. Nine pieces of tissue from each organ were placed on PDA (Potato Dextrose Agar) pre-culturing medium completed with chloramphenicol $(1 \mathrm{~g} / \mathrm{l})$. The plates were kept in the dark at room temperature until the fungal colonies appeared (about 2 weeks).

We analysed the frequencies of colonies to evaluate the fungal colonization in the plants. Then, we selected representative colonies and transferred them to new PDA plates.

In order to isolate homogenous strains, cultures were monosporated or, the non-sporulating ones, monohyphated [23]. We grouped the isolated colonies according to their morphological characters.

\section{Morphotyping}

Fungal colonies were inspected after 1 week, and were then put in morphological groups according to colony appearance, mycelium colour structure, the shape of conidiomata, conidia, and conidiophore.

\section{Statistical evaluation}

To decide whether the observed differences in colonization rates were statistically significant $(\alpha \leq 0.05)$, we used $\chi^{2}$ test when more than 2 samples were compared and z-test for pairwise comparisons. 


\section{Results and discussions}

\section{Colonization rate is influenced by crop management and cultivar}

To find out how soil and growth conditions influence the fungal colonization of bell pepper, we compared two frequently used crop management systems, namely cultivation in natural soil under open field conditions and soil-free cultivation in greenhouse. In both locations, two widely used Hungarian pepper hybrids, 'Hó F1' and 'Kárpia F1' were grown, and we cultivated endophytic fungi from tissue samples (leaf, fruit, root, and stem) from both locations and cultivars. To assess the effect of open field versus greenhouse, we only included the isolates from August and October since the seedlings for both sites had been reared together under greenhouse conditions. For these two time points, we started with a total of 1,607 samples, i.e. with nearly 200 samples per combination (site, cultivar, sampling time), and the number of outgrowing colonies was 436 and 218 from field and greenhouse samples, respectively. As shown in Figure 1A, colonization rates were lower in greenhouse-grown plants.
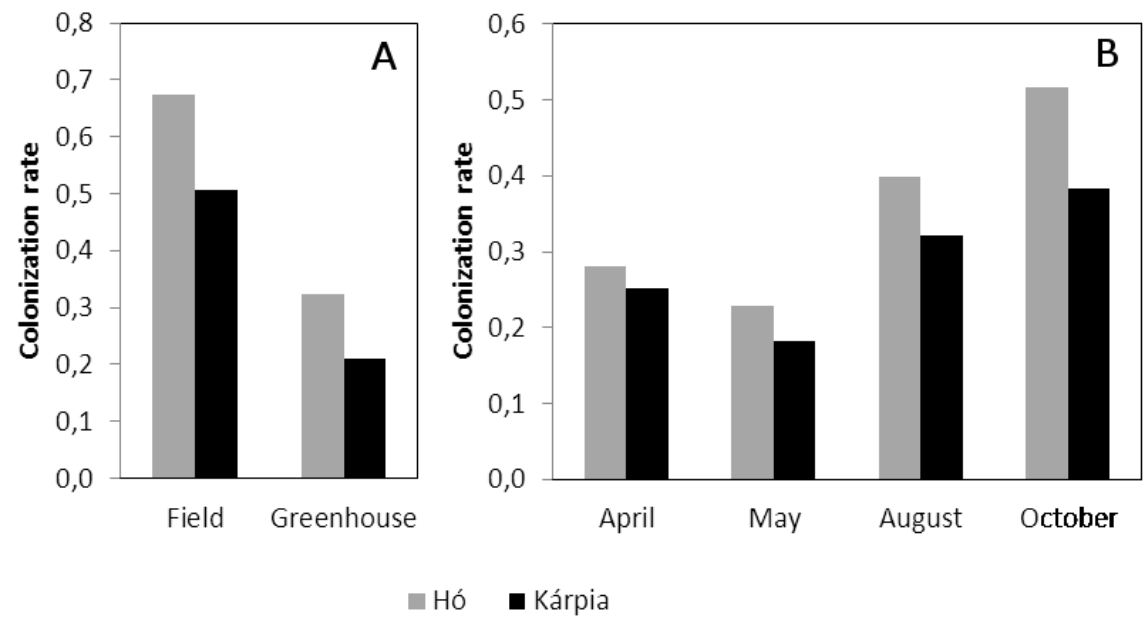

Figure 1. Cultivar, production site, and time-dependent variations of colonization rate

(A) The effect of the production site on fungal colonization was analysed in the samples collected in August and October. Samples from all organs were included in the analysis. Colonization rates in the open field are significantly higher than those in greenhouse-grown peppers. (B) Although there were no changes in colonization rate at the seedling stage (cf. columns for April and May), the colonization rates increased towards the end of the growing season in August 
and peaked in October. There was a difference between the two cultivars in the second half of the year with colonization rates being consistently higher for 'Hó' than for 'Kárpia'.

Statistical evaluation resulted a significant difference between production sites at $\alpha<0.1 \%$ and also between the two cultivars under field conditions, but not in the greenhouse.

\section{Increased colonization rate during the vegetation period}

We also investigated the temporal progression of the overall colonization rate. All samples $(2,260)$ were included in this analysis: in April and in May, they were collected from roots, stems, and leaves; in August and in October, fruits were also included. At the seedling stage, i.e. in April and May, we did not observe any difference in fungal colonization rates, except for a slight decrease in May, which may be a result of extremely fast growth observed at this time (Fig. 1B). The colonization pattern, however, significantly changed in August and October. In these months, we observed a continuous increase in colonization.

To our knowledge, the fungal colonization of $C$. annuum at different developmental stages (seedling, flowering, and fruiting stage) has only been described by Paul et al. [20] to date. For the first two developmental stages, the data we obtained are similar to their results. However, at the fruiting stage, they had observed a considerably more increased colonization rate in all organs than we did. Several explanations are possible. First, the Korean team analysed only fieldgrown plants, under climatic conditions that were different (higher temperature and humidity) from the climatic conditions in Hungary. These factors are known to stimulate fungal infection [13]. Secondly, we included more organs in our studies (e.g. young fruits) that show low colonization, and therefore diminish overall colonization rates. An interesting finding of Paul et al. was the observation that different fungi dominate at different developmental stages [20]. With respect to our morphological groups (see below), we did not observe such association up to now.

\section{Organ-specific differences in colonization rates}

It is known from the literature that many endophytic fungi are specialized to interact with specific organs $[3,4,20]$. Understanding the organ-specific dynamics of fungal community structure might help unravel the physiological role of individual fungal taxa. It is also important because of the health risks connected to infection on the fruits by mycotoxin-producing endophytes [12-14]. This is why, in addition to root, leaf, and stem samples, we have also included in our analysis pedicles, young and old pericarps as well as seeds. 
The results shown in Fig. 2 illustrate that colonization rates of most organs, except for roots and young pericarps, are significantly higher at the end of the vegetation period in October than in August, as expected based on the overall colonization rates. Old leaves and pedicles represent the most strongly colonized organs at the fruiting stage. High colonization of pedicles is possibly interconnected to its porous tissue structure that may accommodate hyphal growth better.

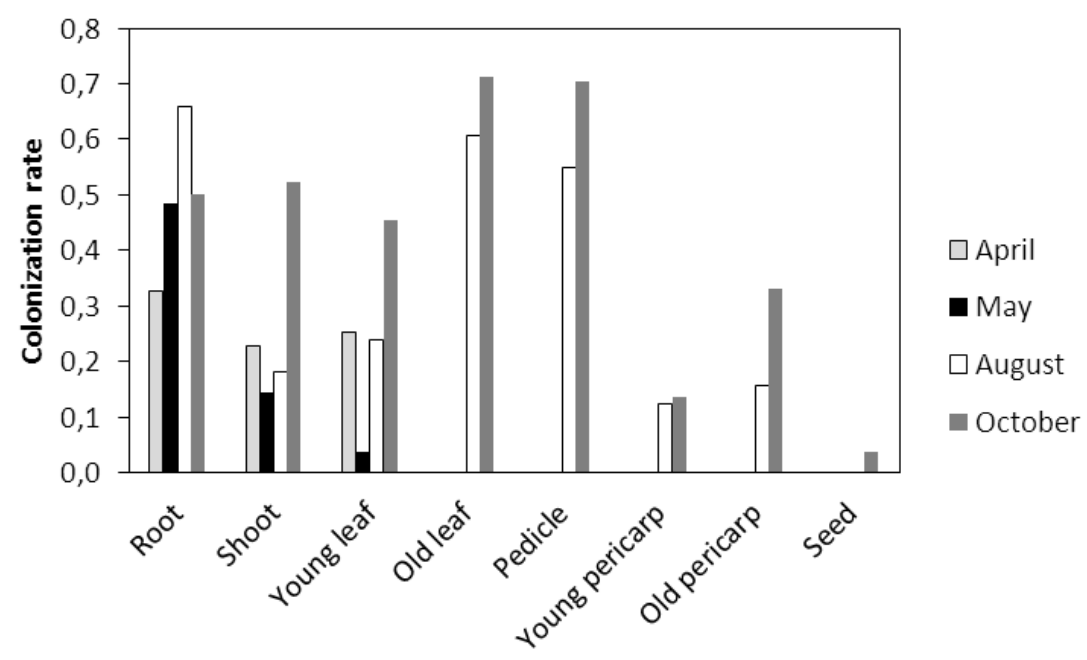

Figure 2. Differences in colonization rates between individual organs

Colonization rates of young and old pericarp tissues were relatively low, although a strong enhancement was observed in the pericarp of fruits nearing biological ripeness in October. Fungal infection of pepper pods, especially that of pericarps, has been reported in Capsicum, and the cancerogenic aflatoxins produced by Aspergillus species are considered a major health risk in chili powder [12-14]. In Hungary, Alternaria sp. was most frequently isolated from mouldy pepper pods [24]. At present, we have no information about the fungal taxa infecting the pericarp of our cultivars. Further analysis, first of all, ITS sequence-based identification of individual endophytes, will be carried out to collect more information about the fungal community structure in bell pepper pods.

Of all investigated organs, roots seem to be the most highly colonized at all sampling times. Although we do not differentiate between production sites in Fig. 2 , it is one of the major goals of our future studies to find out whether and how species composition and richness differ between pepper plants grown in natural soil and pepper plants grown in artificial, soil-free culture, since data in literature 
show that soil conditions may have an effect on the community structure of endophytes [3, 25].

\section{Morphotypes of pepper-colonizing endophytic fungi}

During our investigation, we obtained 809 independent fungal colonies needing taxonomical identification by DNA barcoding. To reduce the amount of samples, we morphotyped our cultures and divided them into groups after each sampling period (eg. into 31 and 29 groups in August and October, respectively). Finally, at the end of the experiment, we classified again all colonies into only 15 larger groups and unique morphotypes. Two of the groups were inhomogeneous, consisting of minor morphological groups with only a few representatives each or of just single, morphologically distinct colonies.

As an example, now we show the morphological diversity of the isolated fungal endophytes in autumn (Fig. 3).

The diagram shows the quantitative distribution and the macromorphological features of the 11 major groups originating from the October sampling. Obviously, the individual groups are not equally represented. Group DA is the largest, making up more than $50 \%$ of the colonies. This is followed by groups DG, DB, DE, and DC, which together with group DA include more than $80 \%$ of isolates. The remaining $20 \%$ is highly heterogeneous. Two segments of the diagram indicate colonies classified into minor morphological groups (18 of the 29) or colonies not classified into any of the groups. Although we are well aware of the pitfalls of morphological classification of microfungi, we believe that our results indicate a relatively large species richness of endophytic fungi with a few dominating taxa. Some preliminary sequencing data seem to confirm this belief.

For further molecular analysis, 118 representative colonies were chosen. They were monosporated/monohyphated and will be classified on the basis of their ITS (internal transcribed region sequence) [26] in experiments that are currently under way. Since the presence of mycoviruses can alter colony morphology as well as the pathogenicity of fungi, several colonies will also be screened for viruses by using a universal, dsRNA-based method for virus detection [27, 28].

Taken together, the results presented in this paper form the basis of the ongoing molecular identification of endophytic fungal taxa and describe the quantitative features of fungal community structure under different culturing conditions during the vegetation period. 

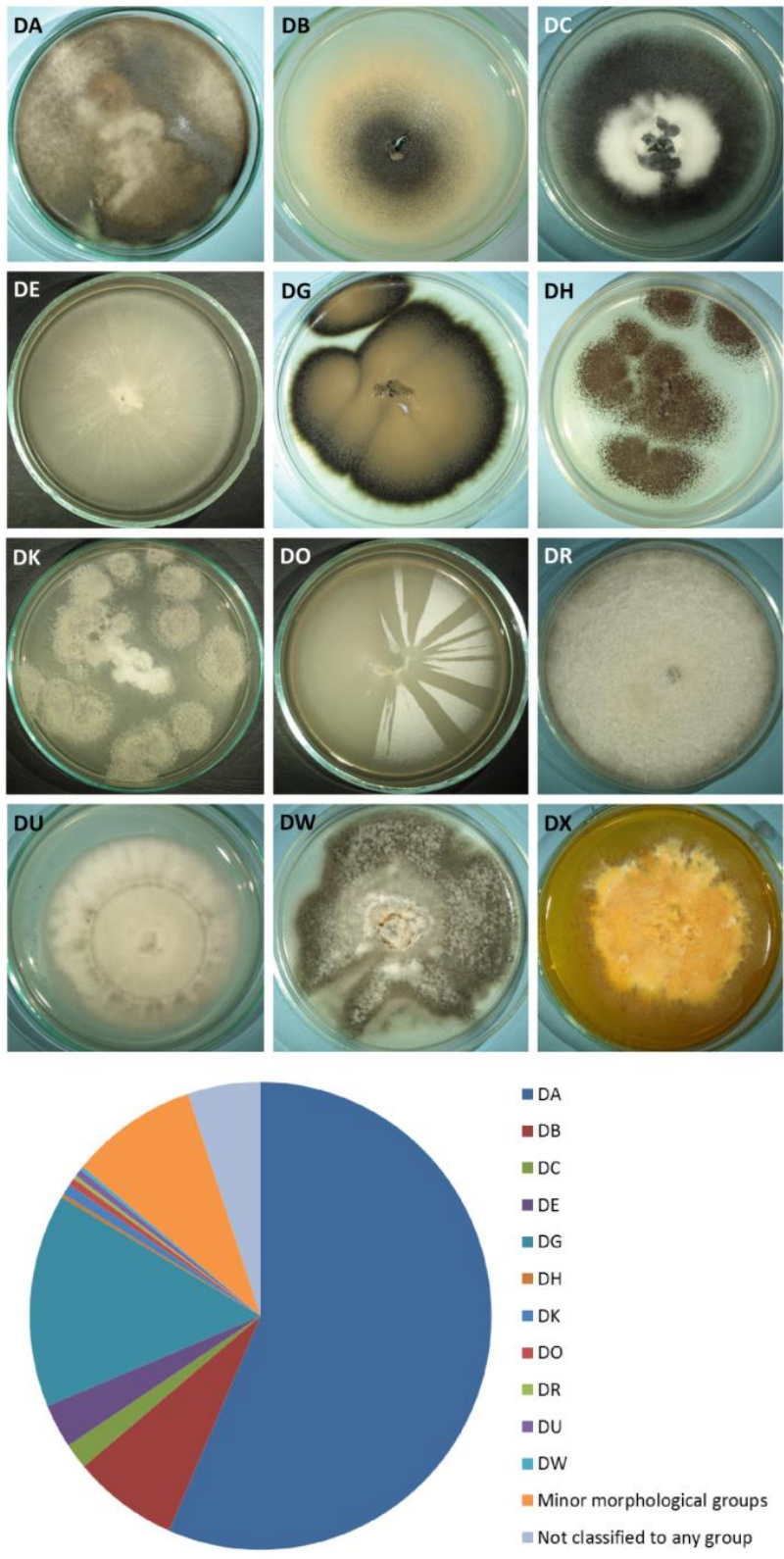

Figure 3. Colony morphology and quantitative representation of fungal morphotypes of colonies from the October sampling period. The colony nominated as DX was arbitrarily chosen from the "Minor morphological group". The endophytic fungal community seems to be dominated by 5 major morphotypes. 


\section{Acknowledgements}

This project was supported by OTKA/NKFI grant 101716. The authors thank Emese Demián for technical help and Orsolya Symmons for helpful comments on the manuscript.

\section{References}

[1] Rodriguez, R. J., White Jr., J. F., Arnold, A. E., Redman, R. S. (2009), Fungal endophytes: diversity and functional roles. New Phytol. 182(2), 314-330.

[2] Redman, R. S., Dunigan, D. D., Rodriguez, R. J. (2001), Fungal symbiosis from mutualism to parasitism: who controls the outcome, host or invader? New Phytol. 151, 705-716.

[3] Hardoim, P. R., van Overbeek, L. S., Berg G., Pirttilä, A. M, Compant, S., Campisano, A., Döring, M., Sessitsch, A. (2015), The hidden world within plants: Ecological and evolutionary considerations for defining functioning of microbial endophytes. Microbiol. Mol. Biol. Rev. 79(3), 293-320.

[4] Berg G., Rybakova D., Grube, M., Köberl M. (2015), The plant microbiome explored: implications for experimental botany. J. Exp. Bot. DOI: 10.1093/jxb/erv466.

[5] Kivlin, S. N., Emery, S. M., Rudgers, J. A. (2013), Fungal symbionts alter plant responses to global change. Am. J. Bot. 100(7), 1445-1457.

[6] Devari, S., Jaglan, S., Kumar, M., Deshidi, R., Guru, S., Bhushan, S., Kushwaha, M., Gupta, A. P., Gandhi, S. G., Sharma, J. P., Taneja, S. C., Vishwakarma, R. A., Shah, B. A. (2014), Capsaicin production by Alternaria alternata, an endophytic fungus from Capsicum annum; LC-ESI-MS/MS analysis. Phytochemistry 98, 183-189.

[7] Baltruschat, H., Fodor, J., Harrach, B. D., Niemczyk, E., Barna, B., Gullner, G., Janeczko, A., Kogel, K. H., Schäfer, P., Schwarczinger, I., Zuccaro, A., Skoczowski, A. (2008), Salt tolerance of barley induced by the root endophyte Piriformospora indica is associated with a strong increase in antioxidants. New Phytol. 180(2), 501-510.

[8] Fávaro, L. C. L., Sebastianes, F. L. S., Araújo, W. L. (2012), Epicoccum nigrum P16, a sugarcane endophyte, produces antifungal compounds and induces root growth, PLoS One 7(6): e36826. DOI:10.1371/journal.pone.0036826.

[9] Lehtonen, P. T., Helander, M., Siddiqui, S. A., Lehto, K., Saikkonen, K. (2006), Endophytic fungus decreases plant virus infections in meadow ryegrass (Lolium pratense). Biol. Lett. 2, $620-623$.

[10] Nair, D. N. Padmavathy, S. (2014), Impact of endophytic microorganisms on plants, environment and humans. The Scientific World Journal. ID: 250693, http://dx.doi.org/10.1155/2014/250693.

[11] Muvea, A. M., Meyhöfer, R., Subramanian, S., Poehling, H. M., Ekesi, S., Maniania N. K. (2014), Colonization of onions by endophytic fungi and their impacts on the biology of Thrips tabaci. PLoS One 9(9): e108242. DOI:10.1371/journal.pone.0108242.

[12] Fazekas, B., Tar, A., Kovács, M. (2005), Aflatoxin and ochratoxin A content of spices in Hungary. Food Addit. Contam. 22 (9), 856-863.

[13] Iqbal, S. Z., Paterson, R. R., Bhatti, I. A., Asi, M. R. (2010), Survey of aflatoxins in chilies from Pakistan produced in rural, semi-rural and urban environments. Food Addit. Contam. PartB Surveill. 3(4), 268-274. 
[14] Iqbal, S. Z., Paterson, R. R., Bhatti, I. A., Asi, M. R., Sheikh, M. A., Bhatti, H. N. (2010), Aflatoxin B1 in chilies from the Punjab region, Pakistan. Mycotoxin Res. 26(3), 205-209.

[15] Hussain, F., Shaukat, S. S., Abid, M., Usman, F., Akbar, M. (2013), Pathogenicity of some important root rot fungi of the chilli crop and their biological control. Int. J. Biol. Biotech., 10(1), 101-108.

[16] Bae, H., Roberts, D. P., Lim, H. S., Strem, M. D., Park, S. C., Ryu, C. M., Melnick, R. L., Bailey, B. A. (2011), Endophytic Trichoderma isolates from tropical environments delay disease onset and induce resistance against Phytophthora capsici in hot pepper using multiple mechanisms. Mol. Plant. Microbe. Interact. 24(3), 336-351.

[17] Hernawati, H., Wiyono, S., Santoso, S. (2011), Leaf endophytic fungi of chili (Capsicum annuum) and their role in the protection against Aphis gossypii (Homoptera: Aphididae). Biodiversitas 12(4), 187-191.

[18] Martinuz, A., Schouten, A., Menjivar, R. D., Sikora, R. A. (2012), Effectiveness of systemic resistance toward Aphis gossypii (Hom., Aphididae) as induced by combined applications of the endophytes Fusarium oxysporum Fo162 and Rhizobium etli G12. Biol. Control 62(3), 206212.

[19] Chaudhary, K. K., Kaul, R. K. (2012), Compatibility of Pausteria penetrans with fungal parasite Paecilomyces lilacinus against root knot nematode on chilli (Capsicum annuum L.). JEBAS. http://www.jebas.org/wp-content/uploads/2014/12/Sample-Paper-JEBAS.pdf.

[20] Paul, N. C., Deng, J. X., Sang, H. K., Choi, Y. P., Yu, S. H. (2012), Distribution and antifungal activity of endophytic fungi in different growth stages of chili pepper (Capsicum annuum L.) in Korea. Plant Pathol. J. 28(1), 10-19.

[21] Khan, A. L., Waqas, M., Hamayun, M., Al-Harrasi, A., Al-Rawahi, A., Lee, I. J. (2013), Cosynergism of endophyte Penicillium resedanum LK6 with salicylic acid helped Capsicum annuиm in biomass recovery and osmotic stress mitigation. BMC Microbiology 13(51). DOI: 10.1186/1471-2180-13-51.

[22] Gange, A. C., Dey, S., Currie, A. F., Sutton, B. C. (2007), Site- and species-specific differences in endophyte occurrence in two herbaceous plants. J. Ecol. 95(4), 614-622.

[23] Choi, Y. W., Hyde, K. D., Ho, W. H. (1999), Single spore isolations of fungi. Fungal Divers. 3, 29-38.

[24] Kovács, J. (2001), Környezeti tényezők hatása a paradicsomalakú paprika magházpenész betegségére, $\mathrm{PhD}$ thesis, University of Veszprém, Keszthely, Hungary.

[25] Glynou, K., Ali, T., Buch, A. K., Kia, S. H., Ploch, S., Xia, X., Çelik, A., Thines, M., MaciáVicente, J. G. (2015), The local environment determines the assembly of root endophytic fungi at a continental scale. Environ. Microbiol. DOI: 10.1111/1462-2920.13112.

[26] White, T. J., Bruns, T., Lee, S., Taylor, J. W. (1990), Amplification and direct sequencing of fungal ribosomal RNA genes for phylogenetics. In: Innis, M. A., Gelfand, D. H., Sninsky, J. J., White, T. J. (eds), PCR Protocols: A guide to methods and applications. Academic Press Inc., New York, 315-322.

[27] Ghabrial, S. A., Suzuki, N. (2009), Viruses of plant pathogenic fungi, Annu. Rev. Phytopathol. 47, 353-384. DOI: 10.1146/annurev-phyto-080508-081932.

[28] Ghabrial, S. A., Castón, J. R., Jiang, D, Nibert, M. L., Suzuki, N. (2015), 50-plus years of fungal viruses. Virology 479-480, 356-368. DOI: 10.1016/j.virol.2015.02.034. 